\title{
Hearing status in patients with overdose of illicit drugs
}

\author{
Farhad Mokhtarinejad ${ }^{1}$, Ali Asghar Peyvandi ${ }^{1}$, Shahin Shadnia ${ }^{2,3}$, Hassan Peyvandi ${ }^{1}$, Manijeh Rezvani ${ }^{3}$, Shahrokh \\ Khoshsirat $^{1}$, Mahbobeh Oroei ${ }^{1 *}$ (1)
}

Received: 23 Dec 2019

Published: 1 May 2021

\section{Abstract}

Background: The overdose of illicit drugs is not always fatal but can lead to various complications. One of the unusual medical complications is a sensorineural hearing loss (SNHL). There are multiple case reports about this subject. Considering the importance of hearing loss on quality of life, we investigated hearing status in patients with overdose of illicit drugs.

Methods: This cross-sectional study was performed in Loghman Hakim hospital in Shahid Beheshti University of Medical Sciences, Tehran, Iran, in 2016-2017. The hearing status of 95 patients with illicit drugs overdose and 44 healthy individuals were assessed using standard pure tone audiometry and distortion product otoacoustic emissions. The patient group was categorized based on hearing status and compared based on some variables. We applied 2 independent $t$ tests, Mann-Whitney, Chi-square, and binary logistic regression tests. All analyses were conducted in Stata 12 (STATA Corp, USA) and significance level was set at less than 0.05 .

Results: We found higher percentage frequency of SNHL in the patient group than the control group $(15.8 \%$ vs $2.3 \%$; $p=0.021)$. The frequency of hearing loss was $21.7 \%$ in opioid users, $5.3 \%$ in stimulant users, and $6.3 \%$ in concomitant use of both. There was a significant relationship between SNHL and overdose of illicit drugs $(\mathrm{aOR}=14.48,95 \% \mathrm{CI}=1.53-136.44 ; \mathrm{p}=0.019)$ with adjusting age, sex, and smoking.

Conclusion: Illicit drugs overdose can potentially affect the hearing system. Opioid drugs, especially methadone and tramadol, have been found to affect the hearing system. Therefore, it is important to conduct longitudinal studies to demonstrate the role of opioid drugs on the hearing system.

Keywords: Hearing Loss, Illicit Drugs, Inner Ear

Conflicts of Interest: None declared

Funding: This study was supported by Shahid Beheshti University of Medical Sciences (IR. Sbmu. RETECH.REC.1395.389)

\section{*This work has been published under CC BY-NC-SA 1.0 license. \\ Copyright $\odot$ Iran University of Medical Sciences}

Cite this article as: Mokhtarinejad F, Peyvandi AA, Shadnia Sh, Peyvandi H, Rezvani M, Khoshsirat Sh, Oroei M. Hearing status in patients with overdose of illicit drugs. Med J Islam Repub Iran. 2021 (1 May);35:56. https://doi.org/10.47176/mjiri.35.56

\section{Introduction}

Illicit drug abuse is one of the most common health problems worldwide. The drugs often induce a pleasurable response in the individuals who desire to use them for reinforcing and rewarding. Acute drug abuse usually occurs as reconsumption after abstinence, accidental and/or intentional consumption (1).

The overdose of illicit drug (OID) has economic and so-

Corresponding author: Dr Mahbobeh Oroei, oroeim@sbmu.ac.ir

1. Hearing Disorders Research Center, Shahid Beheshti University of Medical Sciences, Tehran, Iran

2. Toxicology Research Center, Shahid Beheshti University of Medical Sciences, Loghman Hakim Hospital, Tehran, Iran

3. Loghman-Hakim Hospital Poison Center, Shahid Beheshti University of Medical Sciences, Tehran, Iran cial burdens for the health system due to high morbidity and mortality (2). OID may induce nonlethal complications, such as impairment of central and peripheral nervous system, gastrointestinal, cardiovascular and respiratory system and psychological disturbance (3). Sensorineural hearing loss (SNHL) related to illicit drugs, especially opioid drugs, is another complication that has been report-

$\uparrow$ What is "already known" in this topic:

There were multiple case reports about the occurrence of sensorineural hearing loss with acute and chronic use of illicit drugs. Opioid drugs can potentially affect the hearing system.

\section{$\rightarrow$ What this article adds:}

This study shows an association between the overdose of illicit drugs and sensorineural hearing loss. The opioid drugs, especially methadone and tramadol, are more important in hearing damage. 
ed in multiple case studies (4-11). In animal studies, the presence of opioid receptors in the cochlear system has been demonstrated, but the mechanism of hearing impairment has remained unknown (12-14). To our knowledge, only a few studies have been conducted in this field. Considering the importance of the illicit drugs as a potential ototoxic agent (15) and the effect of hearing loss on quality of life, we aimed to investigate hearing status in patients with OID.

\section{Methods}

This cross-sectional pilot study was conducted from August 2016 to October 2017 in Loghman-Hakim hospital, Tehran, Iran. The ethical committee of Shahid Beheshti University of Medical Sciences approved the study protocol (IR. Sbmu. RETECH.REC.1395.389).

At first, 106 patients were consecutively selected for probing auditory system. Inclusion criteria were illicit drugs overdose, age 15 to 55 years, reluctant to participate in the study, absence of congenital hearing loss or anatomic abnormalities of the head and neck, no history of the skull or neck trauma, noise exposure (occupational/recreational activities), no family history of hearing loss, and no use of known ototoxic medicines (eg, aminoglycosides, salicylates, cisplatin, loop diuretics, and nonsteroid anti-inflammatory) in the past 3 months.

None of the patients had renal insufficiency (plasma creatinine level $>1.4 \mathrm{mg} / \mathrm{dL}$ ), liver problems (elevation in the serum level of liver aminotransferases $>3$ times the upper normal limit), and chronic pain. The patients with drowsiness were excluded from the study. All patients had a positive urine drug screen (UDS) for illicit drugs that were in 3 categories: only opioid drugs, only stimulant drugs, and concomitant use of both drugs. Healthy individuals without a history of ear disease or use of known ototoxic drugs were selected from outpatients as the control group. All participants were examined by ENT specialist to ensure the lack of excessive cerumen and visibility of tympanic membranes. Tympanometry and stapedial reflex (Grason-stadler, Minnesota, USA) were conducted to exclude external and middle ear diseases. We excluded 11 from 106 patients due to their lack of cooperation to continue auditory measurement ( 2 patients), wax impacted in external ear ( 6 patients), and tympanic perforation and mixed hearing loss or conductive hearing loss (3 patients).The remained patients had tympanometry type A. The audiological data of the patient $(n=95)$ and control groups $(n=44)$ were measured with 1 expert audiologist using standard pure tone audiometry (PTA), speech audiometry, and distortion product otoacoustic emission (DPOAE). The DPOAE test (Neurosoft Company) determines cochlea status, especially outer hair cells. Two simultaneous pure tones $\mathrm{f} 1$ and $\mathrm{f} 2$ (with from low to high frequency) were presented to each ear and small sounds (cochlear-generated distortion) coming back from the inner ear were recorded with a sensitive microphone and displayed on the computer screen. The difference between distortion amplitude and noise floor (Signal to Noise Ratio $=\mathrm{SNR}$ ) at the most of test frequencies was equal or more than $6 \mathrm{~dB}$, indicating the presence of DPOAE; otherwise, the test response was absent, showing cochlear dysfunction and in such a case it had to be referred for other diagnostic tests.

PTA (Madsen-Astera) was performed in frequencies 0.25 to $8 \mathrm{KHZ}$ in a standard soundproof room with headphones on the person's ears. The mean of pure tone audiometry threshold $(0.25-8 \mathrm{kHz})$ was compared between the 2 groups studied. To determine the level of hearing loss, the mean of hearing threshold at frequencies $0.5,1,2$, and $4 \mathrm{KHz}$ was calculated based on $\operatorname{BIAP}(16)$. If there was asymmetrical hearing loss, this mean was multiplied in 3 for bad ear and 7 for good ear and then divided by 10 . The calculated threshold more than $20 \mathrm{~dB}$ was considered as hearing loss. The severity of hearing loss is classified to the following class: mild (21-40 dB), moderate (41-70 $d B$ ), sever (71-90 dB), very sever (91-119 dB), and $\geq 120$ $\mathrm{dB}$ total hearing loss (Cophosis) (17). Speech reception threshold (SRT) is measured by speech audiometry that is complementary to PTA. SRT is the lowest threshold, when a patient is able to repeat $50 \%$ of spoken words correctly.

The medical data of the patients (demographic characteristics, cause of OID, history of chronic drugs use, routine laboratory tests, and findings of urine screen) were collected by one of the authors. The procedure of this study was explained to the participants and they were reassured that their information was kept confidential. Informed consent was obtained from all participants.

\section{Statistical analysis}

Quantitative variables were presented with mean and standard deviation. Qualitative variables were expressed as frequency percentage. To compare average hearing threshold between the 2 study group, in the right and left ear, Log-normal transformation was used to make normal data from skewed data and then 2 independent samples $t$ tests were applied. Chi-square (Fisher exact) was used to compare the proportions. Binary logistic regression was applied to determine odds ratio with $95 \%$ confidence interval. The patient group was classified into 2 subgroups based on hearing status (a group with SNHL and another group with normal hearing) and were compared using 2 independent samples $t$ tests and Mann-Whitney U test. All statistical analysis was conducted in Stata 12 (STATA Corp, USA) and significance level was set at less than 0.05 .

\section{Results}

In this study, the hearing status of 95 patients with OID was investigated. There were 60 males $(63.2 \%)$ and 35 females $(36.8 \%)$ with a mean age $30.7 \pm 10.4$ and $25.7 \pm 9.0$ years, respectively $(\mathrm{p}=0.02)$. Most of the patients $(\mathrm{n}=85$, $89.5 \%$ ) consumed drugs orally. A total of 42 patients $(44.2 \%)$ had intentional consumption and the rest of the patients had accidental used. Also, $23(24.2 \%)$ of the patients had a positive history of chronic drugs use.

The urine drug test revealed the presence of opioid drugs in $63.2 \%(n=60)$, stimulant drugs in $20 \%(n=19)$, and concomitant use of both drugs in $16.8 \%$ of the patients $(n=16)$. 
The opioid drugs included methadone $(\mathrm{n}=18,30 \%)$, tramadol $(\mathrm{n}=18,30 \%)$, opium $(\mathrm{n}=8,13.3 \%)$, and others $(\mathrm{n}=16,26.7 \%)$. The stimulant drugs consisted of amphetamine $(n=6,31.6 \%)$, methamphetamine $(n=5,26.3 \%)$, cannabis $(n=3,15.8 \%)$ and amphetamine + methamphetamine $(n=5,26.3 \%)$.

In the patients with concomitant use of both drugs, there were use of methadone in $10(62.5 \%)$, opium in 5 $(31.3 \%)$, tramadol in $1(6.2 \%)$, amphetamine + methamphetamine in 12 patients (75\%), amphetamine in 2 $(12.5 \%)$, and methamphetamine in 2 patients $(12.5 \%)$.

\section{Comparison Between Patients and Control Group}

The mean age of patients was significantly less than the control group $(28.9 \pm 10.2, \quad 37.0 \pm 8.9, \quad$ respectively, $\mathrm{p}<0.001$ ). Male to female ratio was 1.7 and 0.7 in patient and control groups respectively, $(p=0.027)$. Patients had more abundant smoking than the control group $(64.2 \%$ vs $9.1, \mathrm{p}<0.001)$. There was concomitant use of alcohol in 9 patients.
SNHL was found in $15.8 \%$ of the patients $(n=15)$, compared with $2.3 \%$ in the control group (one person) based on BIAP. The mean of pure tone threshold was statistically higher in the patient group than the control group in both ears. Table 1 shows the statistically significant differences in speech reception threshold and the absent DPOAE between the groups. The risk of hearing loss was $8.06(p=0.047)$ in univariate logistic regression. After adjusting for age, gender, and smoking, the risk of hearing loss was $14.48(\mathrm{p}=0.019)$ in patients with OID (Table 2).

\section{Characteristics of Patients With Hearing Loss}

There were 12 male $(80 \%)$ and 3 female $(20 \%)$ patients with SNHL were and they aged between 17 and 54 years. Ten of them had bilateral SNHL. The severity of SNHL, except in 1 patient with moderate SNHL, was mild (Table 3). There was history of chronic drug use (opioids) in 4 patients whose duration of usage was almost 1 to 5 years.

Absent DPOAE response was found in 13 patients $(86.6 \%)$. SRT was between 15 and $40 \mathrm{~dB}$. The majority of

Table 1. Comparison of patient and control groups based on some variables

\begin{tabular}{|c|c|c|c|}
\hline Variable & $\begin{array}{l}\text { Patient group } \\
(\mathrm{n}=95)\end{array}$ & $\begin{array}{c}\text { Control group } \\
(\mathrm{n}=44)\end{array}$ & $\mathrm{p}$ \\
\hline Age $($ Mean \pm SD $)$ & $28.9 \pm 10.2$ & $37.0 \pm 8.9$ & $<0.001$ \\
\hline Male: female (ratio) & $60: 35(1.71)$ & $19: 25(0.76)$ & 0.027 \\
\hline Smoking(n,\%) & $61(64.2)$ & $4(9.1)$ & $<0.001$ \\
\hline \multicolumn{4}{|l|}{$\operatorname{PTA}($ Mean \pm SD $)$} \\
\hline Right & $14.3 \pm 7.1$ & $10.6 \pm 5.8$ & $<0.001$ \\
\hline Left & $14.1 \pm 7.6$ & $10.5 \pm 5.4$ & 0.014 \\
\hline \multicolumn{4}{|l|}{ SRT(Mean \pm SD) } \\
\hline Right & $13.6 \pm 6.3$ & $11.4 \pm 4.3$ & 0.034 \\
\hline Left & $13.2 \pm 6.1$ & $11.4 \pm 6.8$ & 0.044 \\
\hline \multicolumn{4}{|l|}{ DPOAE (Absent) } \\
\hline Right & $69(72.6 \%)$ & $9(33.3 \%)$ & $<0.001$ \\
\hline Left & $69(72.6 \%)$ & $10(37.0 \%)$ & 0.001 \\
\hline
\end{tabular}

Table 2. The risk of sensorineural hearing loss in overdose of illicit drugs

\begin{tabular}{|c|c|c|c|c|c|c|c|c|c|c|}
\hline \multicolumn{4}{|c|}{ Risk of SNHL* } & \multicolumn{4}{|c|}{$\mathrm{OR}(95 \% \mathrm{CI})$} & \multicolumn{3}{|c|}{$\mathrm{p}$} \\
\hline \multirow{2}{*}{\multicolumn{4}{|c|}{$\begin{array}{l}\text { Univariate logistic regression } \\
\text { Multivariate logistic regression }\end{array}$}} & \multicolumn{3}{|c|}{$8.06(1.03-63.12)$} & & \multicolumn{3}{|c|}{0.047} \\
\hline & & & & \multicolumn{3}{|c|}{$14.48(1.54-136.44)^{* *}$} & & \multicolumn{3}{|c|}{0.019} \\
\hline \multicolumn{11}{|c|}{$\begin{array}{l}\text { *SNHL: Sensorineural hearing loss based on International Bureau for Audiophonology ( BIAP), } \\
\text { ** Adjusted OR: Odds ratio with control age, sex and smoking. }\end{array}$} \\
\hline \multicolumn{11}{|c|}{ Table 3. Characteristics of patients with hearing loss } \\
\hline \multirow{2}{*}{ 莺 } & \multirow[t]{2}{*}{$\begin{array}{c}\text { Age } \\
\text { (Years) }\end{array}$} & \multirow[t]{2}{*}{ Sex } & \multirow[t]{2}{*}{ Type of opioid } & \multirow[t]{2}{*}{$\begin{array}{l}\text { History of Chronic } \\
\text { drug use }\end{array}$} & \multicolumn{2}{|c|}{$\begin{array}{l}\text { Mean Hearing } \\
\text { threshold }(\mathrm{dB})\end{array}$} & \multicolumn{2}{|c|}{$\begin{array}{c}\text { DPOAE } \\
\text { (Absent/Present) }\end{array}$} & \multicolumn{2}{|c|}{$\begin{array}{l}\text { SRT } \\
(\mathrm{dB}) \\
\end{array}$} \\
\hline & & & & & Right & Left & Right & Left & Right & Left \\
\hline 1 & 35 & $\mathrm{~F}$ & Amphetamin+ Tramadol & - & 22 & 20 & $\mathrm{~A}$ & $\mathrm{~A}$ & 20 & 20 \\
\hline 2 & 34 & $\mathrm{~F}$ & $\begin{array}{l}\text { Amphetamin+ Metham- } \\
\text { phetamin }\end{array}$ & - & 22 & 22 & $\mathrm{P}$ & $\mathrm{p}$ & 20 & 15 \\
\hline 3 & 48 & M & Methdone & Methadone & 19 & 27 & A & A & 15 & 25 \\
\hline 4 & 41 & M & Methdone+Opium & - & 24 & 23 & A & A & 20 & 20 \\
\hline 5 & 35 & M & Methdone & Methadone & 20 & 25 & $\mathrm{~A}$ & A & 20 & 25 \\
\hline 6 & 31 & M & Methdone & Methadone & 32 & 34 & A & A & 30 & 30 \\
\hline 7 & 18 & M & Tramadol & - & 29 & 29 & A & A & 30 & 25 \\
\hline 8 & 17 & M & Tramadol+ Methdone & - & 44 & 52 & $\mathrm{~A}$ & $\mathrm{~A}$ & 40 & 40 \\
\hline 9 & 33 & M & Tramadol & - & 28 & 22 & A & A & 25 & 20 \\
\hline 10 & 28 & M & Tramadol & - & 25 & 22 & A & A & 20 & 20 \\
\hline 11 & 25 & $\mathrm{~F}$ & Opium & - & 22 & 20 & A & A & 20 & 20 \\
\hline 12 & 54 & M & Tramadol & - & 35 & 32 & $\mathrm{~A}$ & $\mathrm{~A}$ & 30 & 25 \\
\hline 13 & 18 & M & Methdone & - & 23 & 21 & $\mathrm{P}$ & $\mathrm{P}$ & 20 & 20 \\
\hline 14 & 46 & M & Opium & Opium & 23 & 28 & A & A & 25 & 25 \\
\hline 15 & 45 & M & Methdone & - & 19 & 28 & $\mathrm{~A}$ & $\mathrm{~A}$ & 15 & 25 \\
\hline
\end{tabular}

M:Male, F: Female, DPOAE: Distortion product otoacoustic emission, A: Absent, P:Present, SRT: Speech reception threshold.

Mean Hearing threshold is based on BIAP 
those patients had opioid overdose $(n=13,86.6 \%)$. Figure 1 shows remarkable SNHL in opioid users, with methadone and tramadol having the most proportion. SNHL in stimulant drug users was $5.3 \%$, and one patient had consumed amphetamine with methamphetamine. Also, 1 patient was opioid + stimulant drug user.

\section{Subgroup Analysis}

There were no significant differences in terms of gender and age between patients with or without SNHL (Table 4). The risk of SNHL was more in the overdose of opioid drugs than other drug overdoses $(\mathrm{OR}=4.56,95 \% \mathrm{CI}=0.96$ $21.58, \mathrm{p}=0.045$ ).

The proportion of absent DPOAE response was similar in the 2 groups $(\mathrm{p}=1.00)$. From the $69(72.6 \%)$ patients with a present DPOAE response, only 11 had abnormal PTA. In addition, we analyzed some of the hematological parameters in those subgroups. The hemoglobin level, platelet count, and white blood cell count had a significant relationship with SNHL (Table 4) that were less in patients with SNHL as compared with patients with normal hearing.

\section{Discussion}

The patients with OID who survive may suffer various complications, one of which can be sensorineural hearing loss. In this study, we found considerable cases of SNHL in the patients with OID compared with the control group. There were significant increases in auditory threshold and speech reception threshold for both ears of the patients. The proportion of absent DPOAE response was more in the patient group than the control group. The risk of SNHL was 15 -folds in the patient group after adjusting for age, gender, and smoking. This finding shows that the overdose of illicit drugs can negatively affect the hearing system. Considering the wide confidence interval of this risk, it should be confirmed with more participants in the future studies. The majority of the patients with SNHL

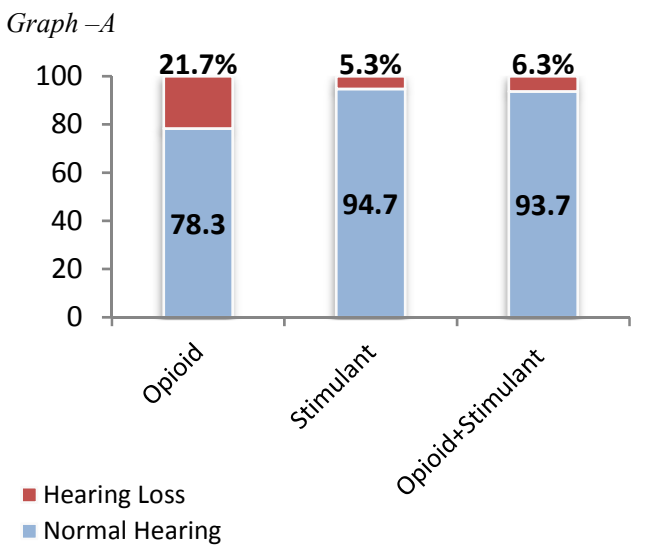

Graph $-B$

Fig. 1. Sensorineural hearing loss rate in three groups of illicit drugs (Graph -A) \& frequency percentage of sensorineural hearing loss in opioid users (Graph -B)

Table 4.Comparison of various variables between patients with and without hearing loss

\begin{tabular}{|c|c|c|c|}
\hline Variables & Normal hearing $(\mathrm{n}=80)$ & Hearing loss $(n=15)$ & $\mathrm{p}$ \\
\hline Male (n, \%) & $48(60)$ & $12(80)$ & 0.242 \\
\hline Age $($ Mean \pm SD $)$ & $27.9 \pm 9.6$ & $34.2 \pm 11.8$ & 0.066 \\
\hline Opioid drug (n, \%) & $47(58.7)$ & $13(86.7)$ & $0.045^{*}$ \\
\hline Smoking $(\mathrm{n}, \%)$ & $52(65)$ & $9(60)$ & 0.773 \\
\hline Consumption of alcohol & $7(8.9)$ & $2(13.3)$ & 0.632 \\
\hline DPOAE. Absent (n, \%) & $58(72.5)$ & $11(73.3)$ & 1.000 \\
\hline SRT. Right & $11.8 \pm 4.2$ & $23.3 \pm 6.7$ & $<0.001 *$ \\
\hline SRT. Left & $11.2 \pm 3.5$ & $23.7 \pm 5.8$ & $<0.001 *$ \\
\hline $\mathrm{Hb}(\mathrm{g} / \mathrm{dL})$ & $13.7 \pm 1.9$ & $12.5 \pm 2.1$ & $0.037 *$ \\
\hline $\mathrm{MCV}$ & $86.7 \pm 5.6$ & $86.7 \pm 6.0$ & 0.797 \\
\hline $\mathrm{MCH}$ & $29.7 \pm 2.5$ & $29.2 \pm 2.6$ & 0.414 \\
\hline $\mathrm{MCHC}$ & $34.3 \pm 1.7$ & $33.6 \pm 0.9$ & 0.075 \\
\hline RDW & $12.9 \pm 1.3$ & $13.5 \pm 1.6$ & 0.254 \\
\hline $\operatorname{WBC}\left(10^{3} / \mathrm{u}\right)$ & $12.1 \pm 4.3$ & $8.3 \pm 3.3$ & $0.002 *$ \\
\hline Neutrophil $\left(10^{3} / \mathrm{u}\right)$ & $74.0 \pm 14.1$ & $63.4 \pm 17.4$ & $0.014^{*}$ \\
\hline Lymphocyte $\left(10^{3} / \mathrm{u}\right)$ & $19.3 \pm 12.1$ & $27.0 \pm 13.2$ & $0.023^{*}$ \\
\hline Platelet $\left(10^{3} / \mathrm{u}\right)$ & $249.0 \pm 54.9$ & $213.1 \pm 103.4$ & $0.030 *$ \\
\hline PDW & $13.1 \pm 2.0$ & $13.9 \pm 1.9$ & 0.143 \\
\hline MPV & $10.3 \pm 1.0$ & $10.7 \pm 1.0$ & 0.308 \\
\hline $\operatorname{AST}(\mathrm{U} / \mathrm{L})$ & $31.8 \pm 37.1$ & $35.5 \pm 39.1$ & 0.318 \\
\hline ALT (U/L) & $26.5 \pm 28.0$ & $30.3 \pm 32.2$ & 0.582 \\
\hline BUN (mg/dL) & $30.1 \pm 19.9$ & $29.3 \pm 8.8$ & 0.576 \\
\hline $\mathrm{Cr}(\mathrm{mg} / \mathrm{dL})$ & $1.03 \pm 0.3$ & $1.02 \pm 0.2$ & 0.602 \\
\hline
\end{tabular}

DPOAE: distortion product otoacoustic emission, SRT: Speech reception threshold

All comparisons are conducted with Mann -Whitney U test except hemoglobin is compared with two independent t- test.

Starred items are significant $(\mathrm{P}-\mathrm{value}<0.05)$ 
were males with the mean age of younger than 50 years and the first time of illicit drug usage. The severity of SNHL was mild (except in 1 patient) and subjective hearing problems were not observed in the patients. A 17year-old male with moderate SNHL used methadone and tramadol. Most of discovered SNHL was bilateral with absent DPOAE response. The proportion of SNHL was more in the patients with opioid drugs than other drugs. The most common illicit drugs in the patients with SNHL were methadone and tramadol. Few cases of SNHL were from stimulant drug users $(5.3 \%$ : only stimulant drugs; $6.3 \%$ : stimulant together with opioids), whereas Igbal's study reported $16.4 \%$ SNHL in patients with long-term use of stimulant drugs (5). That difference can be explained by groups studied and method of hearing assessment. We detected no relationship between SNHL and demographic data in the patient group. On the contrary, evidence shows that smoking and alcohol consumption have a positive association with SNHL, especially in combination with analgesic drugs $(18,19)$, but it was not statistically confirmed in our study.

Based on our knowledge, there were no comparable studies to confirm or disconfirm our findings, because overall studies were case reports on the overdose or longterm use of illicit drugs. Rawool et al in 2011 reported the relationship between opium addiction and hearing loss, but their participants were chronic substance users and experienced severe recreational noise, while our participants had no history of exposure to recreational noise and were only a limited number of chronic consumers. Cochlear dysfunction is a possible mechanism in patients with SNHL. Nguyen et al have investigated the multiple case reports of SNHL caused by opioid use and suggested possible mechanisms (21). Proposed mechanisms include inhibition of adenylate cyclase activity in hair cells of cochlea, vasospasm, allergic reaction or vacuities, genetic mutation in transport proteins, receptors and/or metabolizing enzymes(20-22). Our analysis showed the low level of white blood cell and platelets in patients with SNHL, which is not consistent with the theory of making an inflammatory process in the inner ear. Some case studies have reported no response to corticosteroids in SNHL associated with opioids $(4,23,24)$. A theory of microvascular pathology and a decrease in the blood flow of the cochlea is another proposed theory $(9,24,25)$.We found no significant association between SNHL with smoking and the mean corpuscular volume (MCV), which is not compatible with microvascular pathology. Those findings can be supported with measuring various biomarkers as endothelin-1, which is a vasoconstrictor produced by vascular endothelial cells in opioid stimulation. The low hemoglobin in patients with SNHL versus those with normal hearing can be addressed to possible roles of anemia on hearing loss (26) that requires more detailed investigations in the future.

We propose that SNHL can be related to individual susceptibility due to genetic variations in blood-labyrinth barrier transport channels, metabolizing enzymes and/or opioid receptors function (21) because the age of our patients was less than the age of presbycusis (27). Blood- labyrinth barrier has an important role in maintaining elements of inner ear fluid and regulating hemostatic. Genetic variation in channels and/or disruption of this barrier could lead to inner ear fluid imbalance and toxic concentration in cochlea. Multiple experimental studies have demonstrated the presence of opioid receptors (mu, delta, and kappa) in neural fibers and spiral ganglion of cochlea. These receptors are also present in inner and outer hair cells. The stimulation of opioid receptors may inhibit adenylate cyclase in cochlea $(12-14,20)$. Illicit drugs are metabolizing by cytochrome P450 enzymes and carboxyl esterase in liver. These enzymes have allelic variant in the various individuals, so some people can be rapid metabolizers or poor metabolizers (21).

However, based on our findings there are probable mechanisms, but we think the intake of high-dose illicit drugs, especially opioids, in susceptible individuals, may affect the hearing system through mechanisms, such as dysfunction of blood-labyrinth barrier and/or sudden stimulation of opioid receptors in auditory pathway. According to some evidence of the effects of opioids on inner ear, more studies should be done to confirm the discussed theories.

\section{Strength, Limitation, and Recommendation}

We screened hearing sensitivity by the PTA and DPO$\mathrm{AE}$ in patients with OID who did not have any symptoms of hearing system. Limitations of our study should be addressed. First, one limitation was small sample size. Second, we did not investigate the dosage of illicit drugs because patients' information was not reliable. The role of methadone and tramadol in the auditory system can be a guide for more studies in the future. In addition, use of electrocochleography (ECOG) and auditory brainstem response $(\mathrm{ABR})$ is recommended to obtain more information on auditory nerve function.

\section{Conclusion}

The use of illicit drugs can cause various medical problems, one of which is sensorineural hearing loss, whose mechanism has remained unknown. This study showed a risk of sensorineural hearing loss after the overdose of illicit drugs, especially methadone and tramadol.

\section{Acknowledgement}

The authors are grateful for the cooperation of colleagues at Toxicology Research Center, Audiology Department, and Clinical Research Development Center in Loghman Hakim hospital.

\section{Conflict of Interests}

The authors declare that they have no competing interests.

\section{References}

1. Bott R. World drug report. Igarss 2014. 2015.

2.Li W, Gunja N. Illicit drug overdose--prevalence and acute management. Aust Fam Physician. 2013 Jul;42(7):481-5.

3. Ricardo Buenaventura M, Rajive Adlaka M, Nalini Sehgal M. Opioid complications and side effects. Pain Physician. 2008;11:S105-S20. 
4. Ho T, Vrabec J, Burton A. Hydrocodone use and sensorineural hearing loss. Pain Physician. 2007;10(3):467-72.

5. Iqbal N. Hearing loss in amphetamine users. J Psychoactive Drugs. 2002;34(4):401-7.

6. Lupin A, Harley C. Inner ear damage related to propoxyphene ingestion. CMAJ. 1976;114(7):596.

7. Nair EL, Cienkowski KM, Michaelides E. The impact of sudden hearing loss secondary to heroin overdose on fitting outcomes. Am J Audiol. 2010;19(2):86-90.

8. Saifan C, Glass D, Barakat I, El-Sayegh S. Methadone induced sensorineural hearing loss. Case Rep Med. 2013;2013.

9. Schrock A, Jakob M, Wirz S, Bootz F. Sudden sensorineural hearing loss after heroin injection. Eur Arch Otorhinolaryngol. 2008;265(5):603-6.

10. Schweitzer VG, Darrat I, Stach BA, Gray E. Sudden bilateral sensorineural hearing loss following polysubstance narcotic overdose. J Am Acad Audiol. 2011;22(4):208-14.

11. Shaw KA, Babu KM, Hack JB. Methadone, another cause of opioidassociated hearing loss: a case report. J Emerg Med. 2011;41(6):6359.

12. Jongkamonwiwat N, Phansuwan-Pujito P, Casalotti SO, Forge A, Dodson H, Govitrapong P. The existence of opioid receptors in the cochlea of guinea pigs. Eur J Neurosci. 2006;23(10):2701-11.

13. Jongkamonwiwat N, Phansuwan-Pujito P, Sarapoke $P$, Chetsawang $\mathrm{B}$, Casalotti SO, Forge A, et al. The presence of opioid receptors in rat inner ear. Hear Res. 2003;181(1):85-93.

14. Popper P, Cristobal R, Wackym P. Expression and distribution of $\mu$ opioid receptors in the inner ear of the rat. Neuroscience. 2004;129(1):225-33.

15. Oroei M, Peyvandi AA, Mokhtarinejad F. Opioid Drugs and Sensorineural Hearing Loss. Addict Health. 2018 Jan;10(1):64-6.

16. Monteiro T, Christmann R, Bonfá E, Bento R, Novalo-Goto E, Vasconcelos L. Hearing loss in diffuse cutaneous systemic scleroderma. Scand J Rheumatol. 2011;40(6):467-71.

17. Monteiro TA, Christmann RB, Bonfa E, Bento RF, Novalo-Goto ES, Vasconcelos LG. Hearing loss in diffuse cutaneous systemic scleroderma. Scand J Rheumatol. 2011 Nov;40(6):467-71.

18. Jun HJ, Hwang SY, Lee SH, Lee JE, Song JJ, Chae S. The prevalence of hearing loss in South Korea: Data from a population-based study. Laryngoscope. 2015;125(3):690-4.

19. Cruickshanks KJ, Klein R, Klein BE, Wiley TL, Nondahl DM, Tweed TS. Cigarette smoking and hearing loss: the epidemiology of hearing loss study. JAMA. 1998;279(21):1715-9.

20. Rawool V, Dluhy C. Auditory sensitivity in opiate addicts with and without a history of noise exposure. Noise Health. 2011;13(54):356.

21. Nguyen K, Lopez I, Ishiyama G, Ishiyama A. Review of opioidassociated hearing loss and possible mechanism of opioid-mediated endothelin-1-dependent cochlear vasoconstriction. J Otol Rhinol. 2014;2:2

22. Vorasubin N, Calzada AP, Ishiyama A. Methadone-induced bilateral severe sensorineural hearing loss. Am J Otolaryngol. 2013;34(6):7358 .

23. Friedman RA, House JW, Luxford WM, Gherini S, Mills D. Profound hearing loss associated with hydrocodone/acetaminophen abuse. Otol Neurotol. 2000;21(2):188-91.

24. Freeman SR, Bray ME, Amos CS, Gibson WP. The association of codeine, macrocytosis and bilateral sudden or rapidly progressive profound sensorineural deafness. Acta Oto-Laryngol 2009; 129(10):1061-6.

25. Tang Ho M. Hydrocodone use and sensorineural hearing loss. Pain Physician. 2007;10:467-72.

26. Schieffer Kathleen M, Chuang Cynthia H, Connor James, Pawelczyk James A, Sekhar Deepa L. Association of iron deficiency anemia with hearing loss in US adults. JAMA Otolaryngol Head Neck Surg. 2017;143(4):350-4.

27. Huang Q, Tang J. Age-related hearing loss or presbycusis. Eur Arch Oto-Rhino-L. 2010;267(8):1179-91. 